\title{
Fermilab
}

Managed by Fermi Research Alliance, LLC for the U.S. Department of Energy Office of Science

\section{Driving Strategic Alliance with Best Practices}

Tammy Whited

NLIT 2018

24 May 2018

FERMILAB-SLIDES-18-045-CD

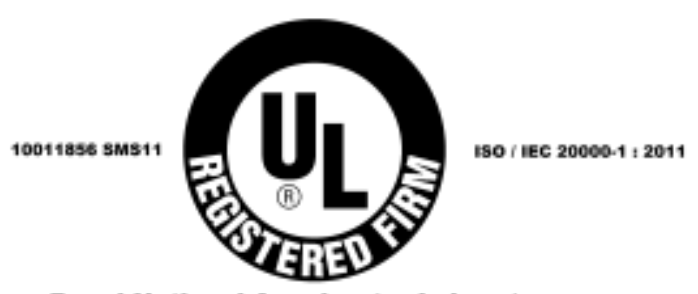

Fermi National Accelerator Laboratory

This manuscript has been authored by Fermi Research Alliance, LLC under Contract No. DE-AC02-07CH11359 with the U.S. Department of Energy, Office of Science, Office of High Energy Physics. 


\section{Driving Strategic Alignment With Best Practices}

Tammy Whited, Head of Service Management, OCIO, Fermi National Accelerator Laboratory (Fermilab)

Do you have a strategic and trusted relationship with your business partners? Does your leadership team have the right capabilities, competencies and skills to deliver on what the business needs? Discover how Fermilab uses best practice frameworks and standards such as ITSM, Enterprise Architecture and ISO to enable a strategic approach to IT management. Find out details on Fermilab's Service Strategy and Service Design roadmap and how they achieved success in their strategic alignment with the business of science. 


\section{About Fermilab}

Fermilab is America's particle physics and accelerator laboratory.

Our vision is to solve the mysteries of matter, energy, space and time for the benefit of all

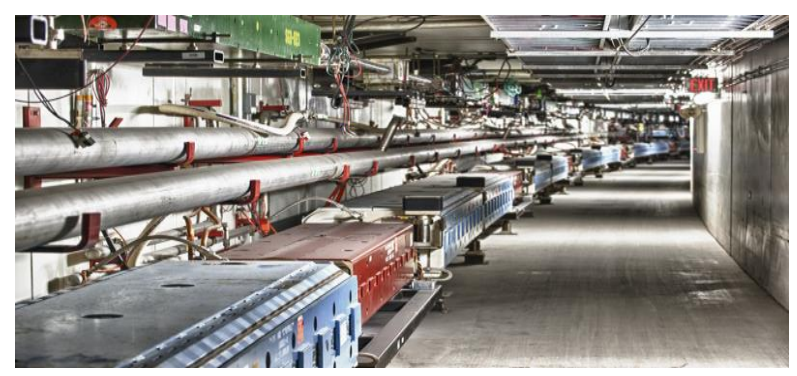

We use these machines to search for the smallest things we can find in nature, and learn more about them. The goal is to find out more about how

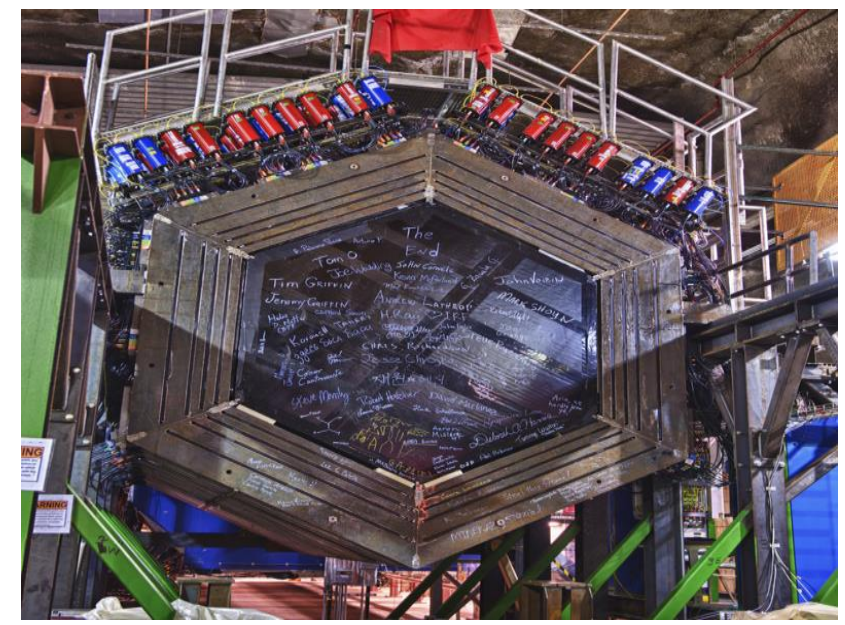

We build enormous particle accelerators and gigantic particle detectors. the universe works.

\section{Long Baseline Neutrino Facility / DUNE}

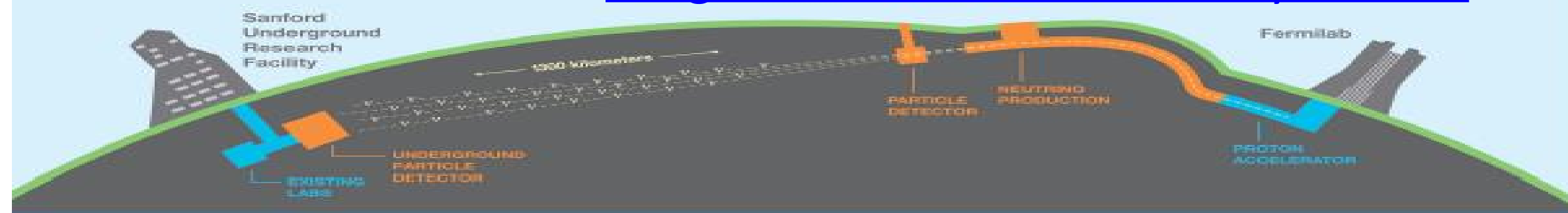




\section{Agenda}

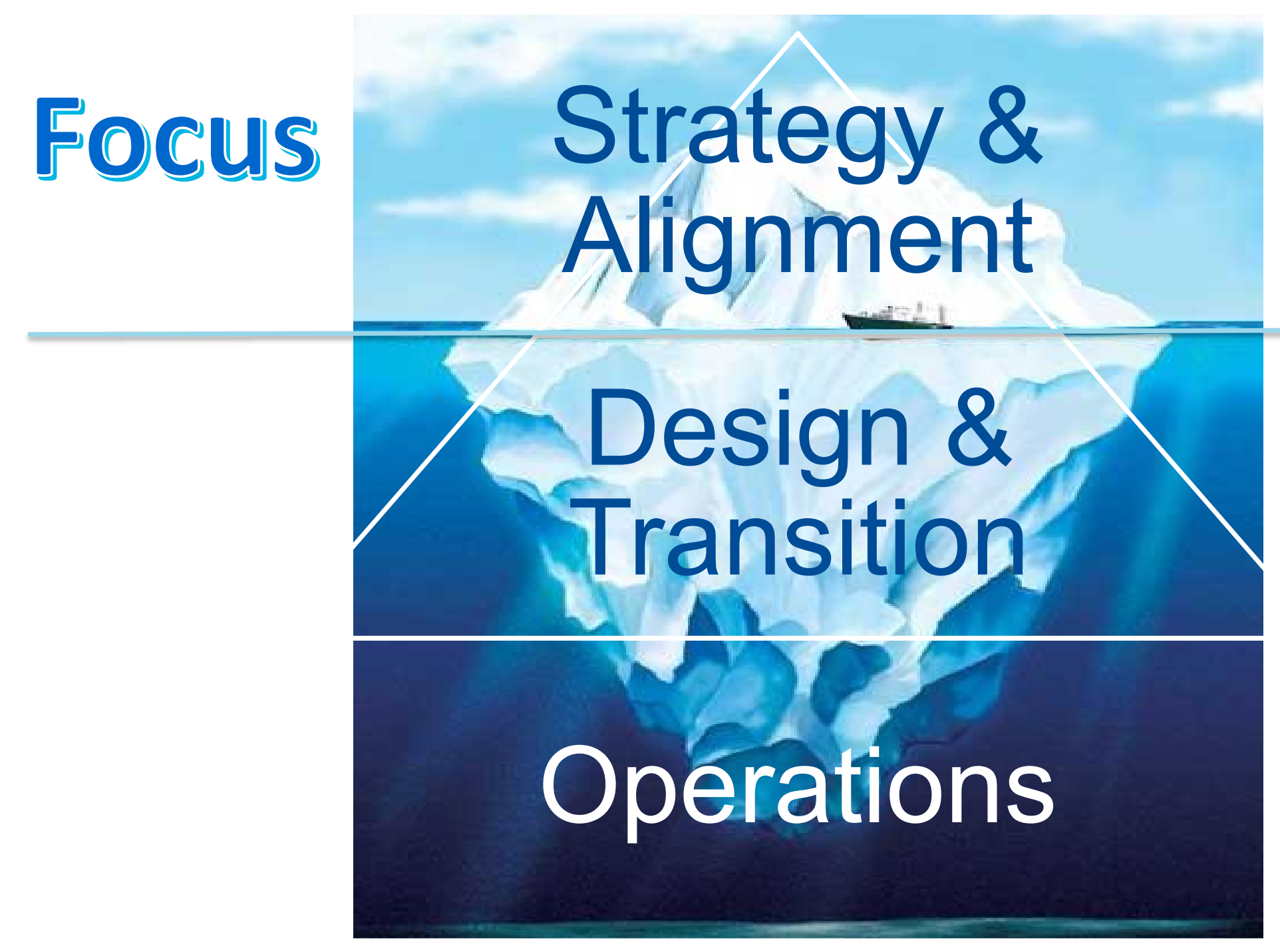




\section{Fermilab's Service Management Journey}

Why ITSM?
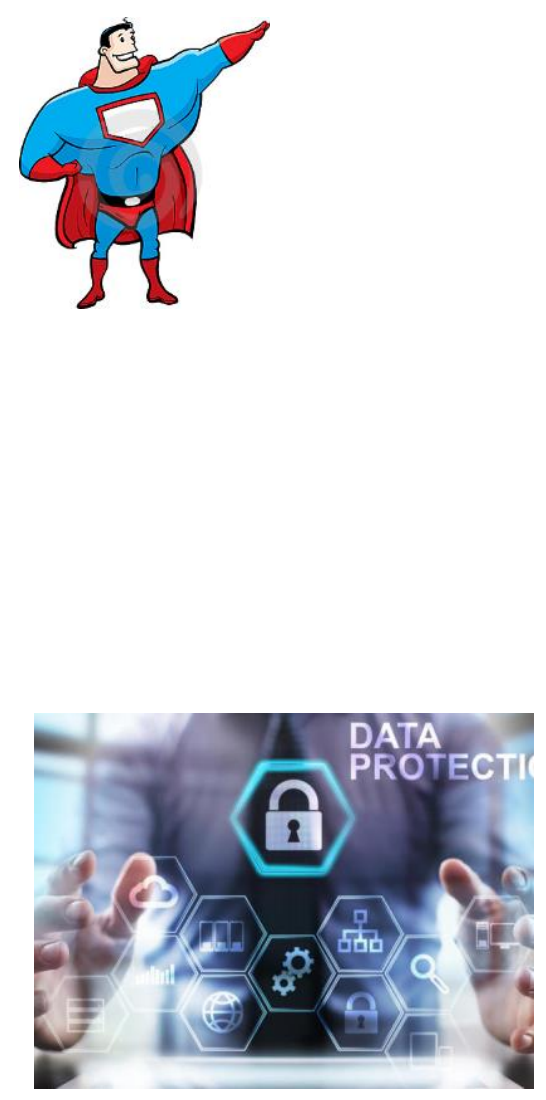
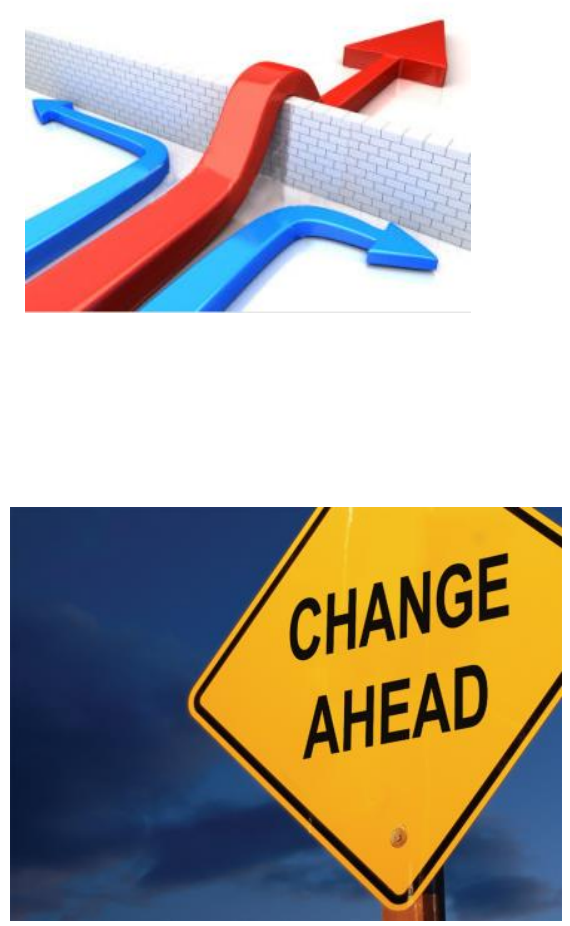
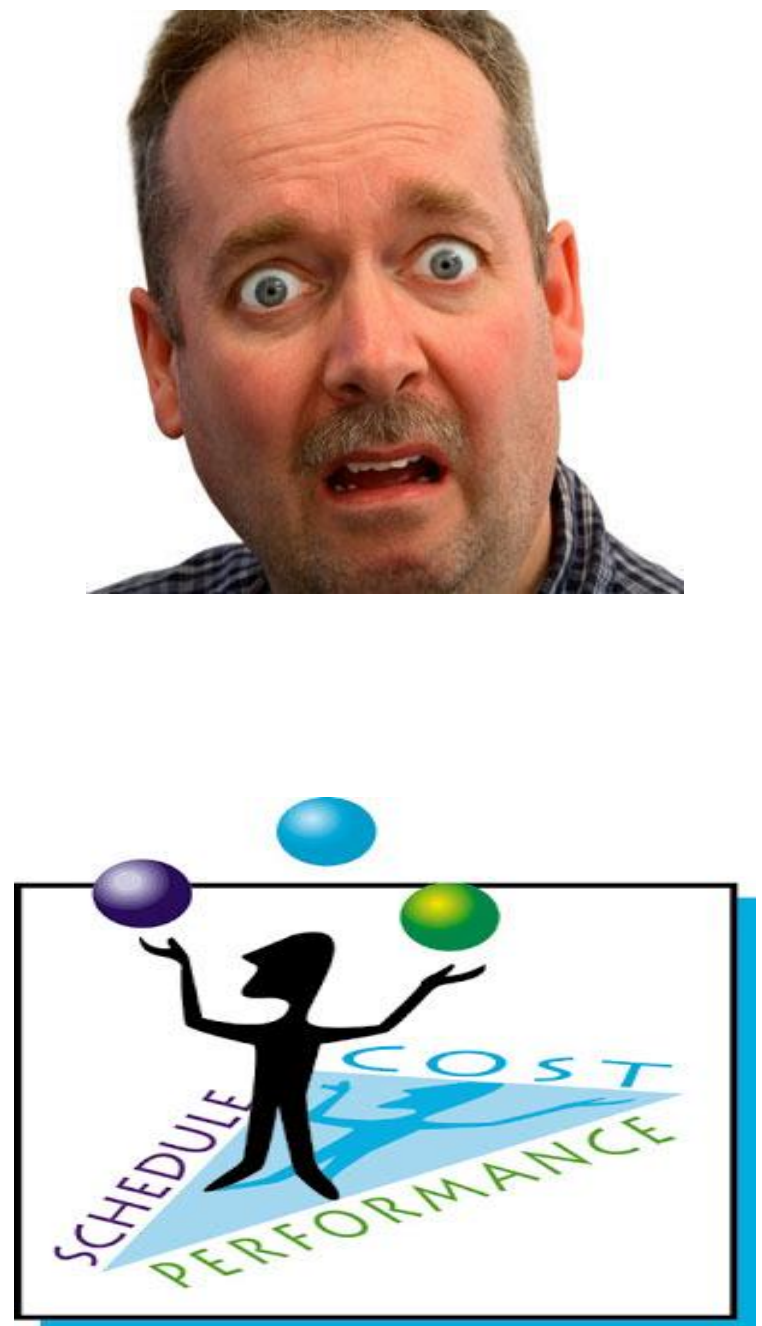

\section{葉Fermilab}




\section{Fermilab's ITSM Journey}

\section{8}

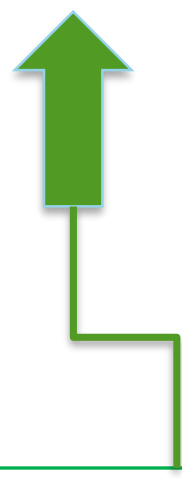

- Consolidation

- Common Terminology

- Building Processes

- Getting buy-in

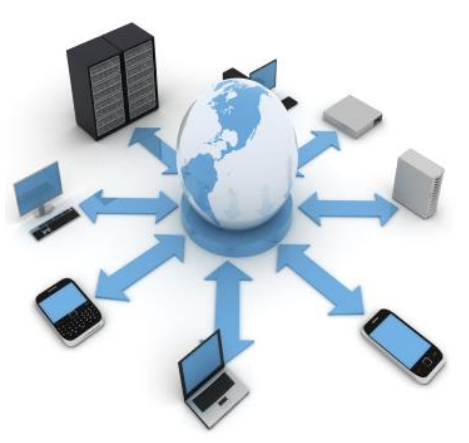

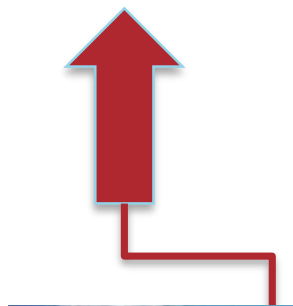

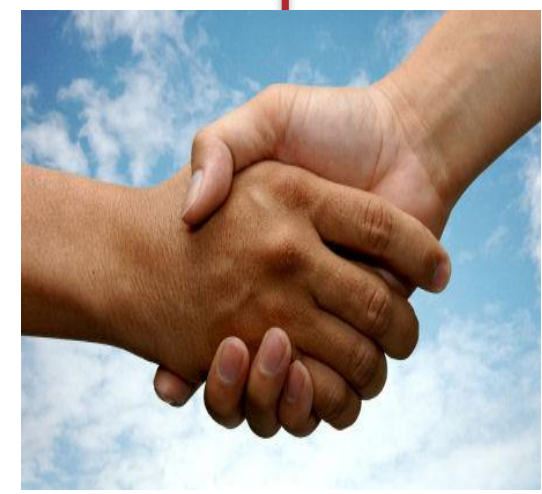

Established

- Service

Management Office

- Business

Relationship

Management
- Functioning IT Management System

- Service Design, Service Transition and Service Operations

- CSIP

- ISO20K Recertified

- Org Change Mgmt 


\section{North Star}

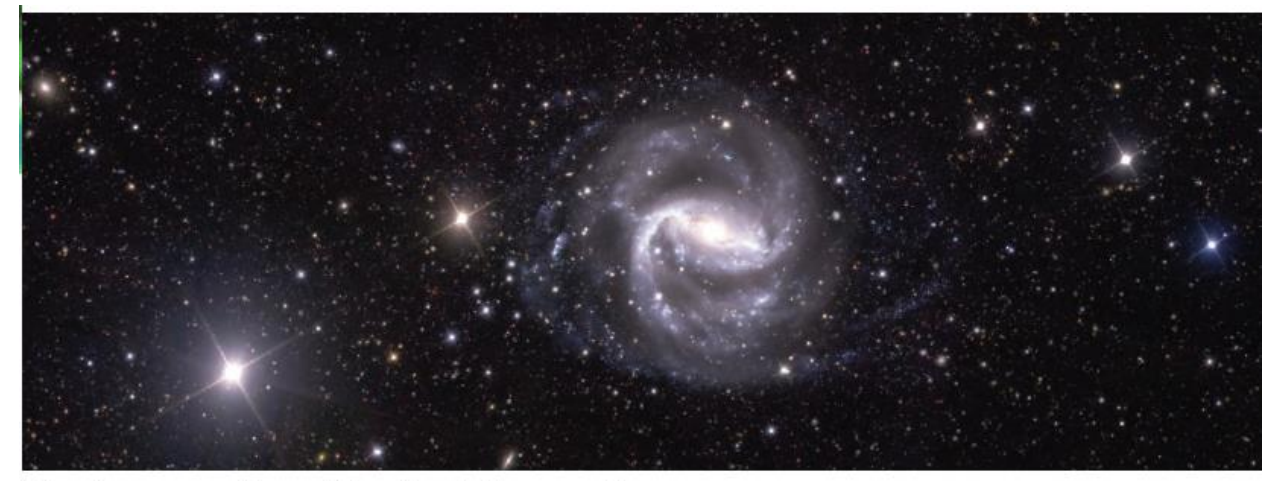

Sky imagery from the Dark Energy Survey
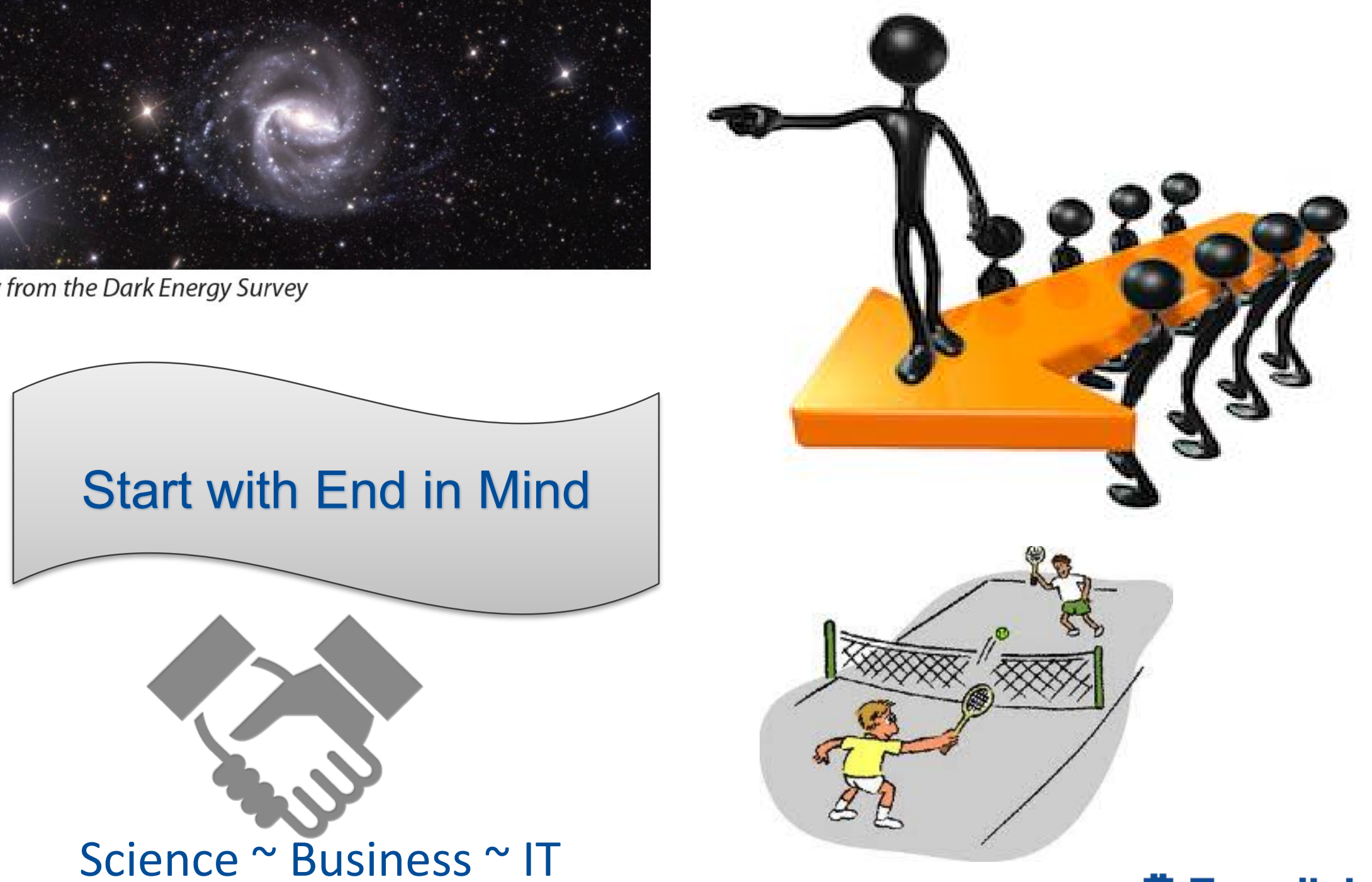

荤 Fermilab 


\section{Progression Analogy}

1. Consistency

2. Control

3. Depth

4. Spin

5. Power
1. Operations

2. Transition

3. Design

4. Strategy

5. Continuous Improvement

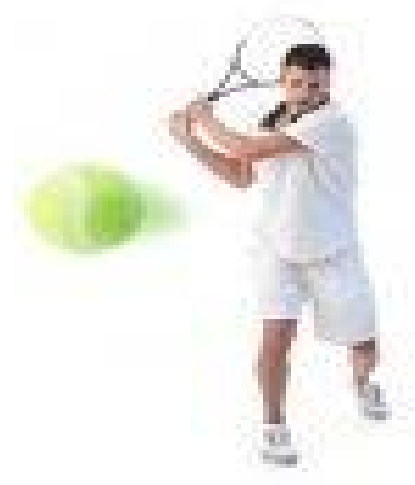

Tennis Stroke

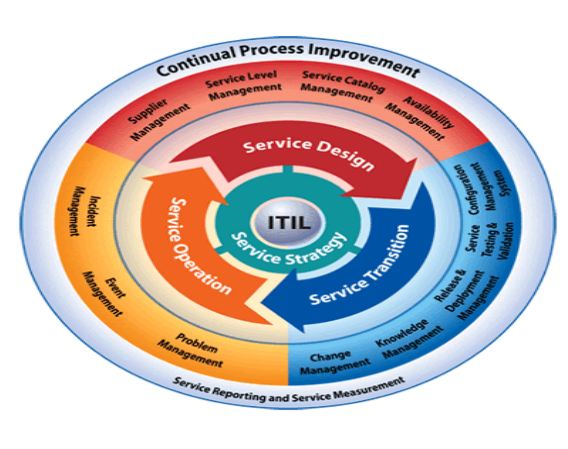

Service Management 


\section{Fundamental Building Blocks}

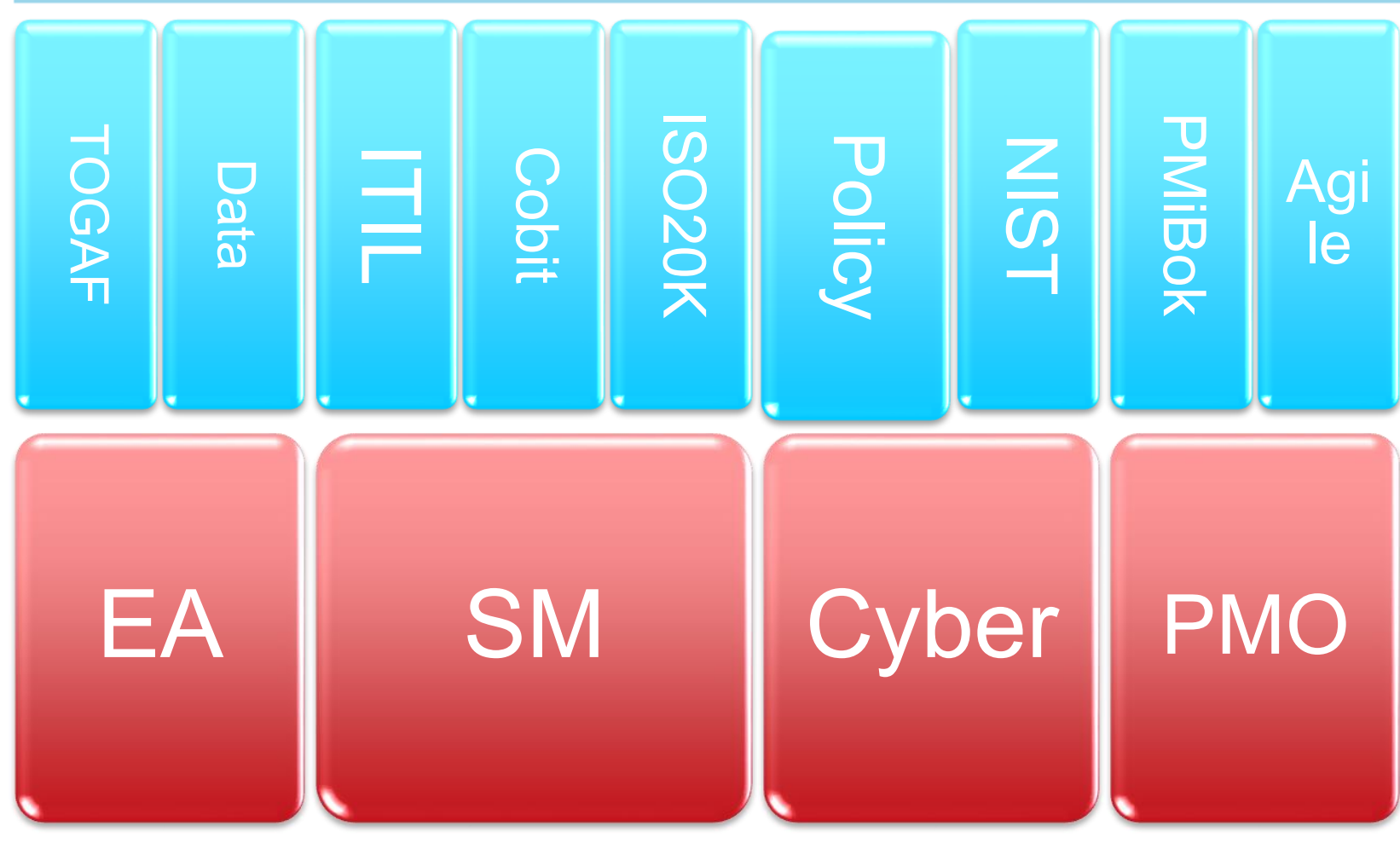

\section{Organization Change Management}

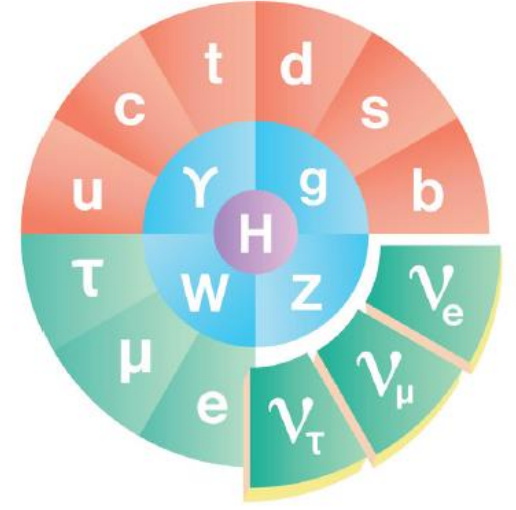

FUNDAMENTAL

Neutrinos are fundamental particles, which means that-like quarks and photons and electrons-they cannot be broken down into any smaller bits. 


\section{Developing the Fundamentals}

We work hard to ensure that our computing workforce are aware of the fundamentals and we have a few requirements that help us to ensure this.

- Investment in staff training is key

- ITIL v3 1/2 day training for service owners/providers

- ITIL v3 foundation certification for process owners and service owners if they are interested

- Monthly service owner training

- Regular check points with computing management to ensure we are aligned with the fundamentals

- Integrate fundamentals in how we do business, with strong management support 


\section{Strategy Mechanics}

- Development and maintenance of a Strategic Plan

- Computing Operating Model

- Development of Financial Cost Model to understand the true cost of providing Computing services

- Expanded use our Demand Management and Portfolio Management processes and tools to capture, evaluate and prioritize all demands or requests

- Strategic partners through our Business Relationship Management process

- Manage Organization Change for all IT projects

- Implementation and management of Enterprise Architecture

- Robust Cyber Security program 


\section{Strategic Plan}

\section{Computing Mission}

- Deliver timely, innovative computing solutions and services that enable Fermilab to achieve its scientific mission; efficiently execute the business of the laboratory and provides a modern user experience.

\section{Computing Vision}

- Provide secure and reliable access to information and services, any time, any place, on any device, in full collaboration with our scientific community
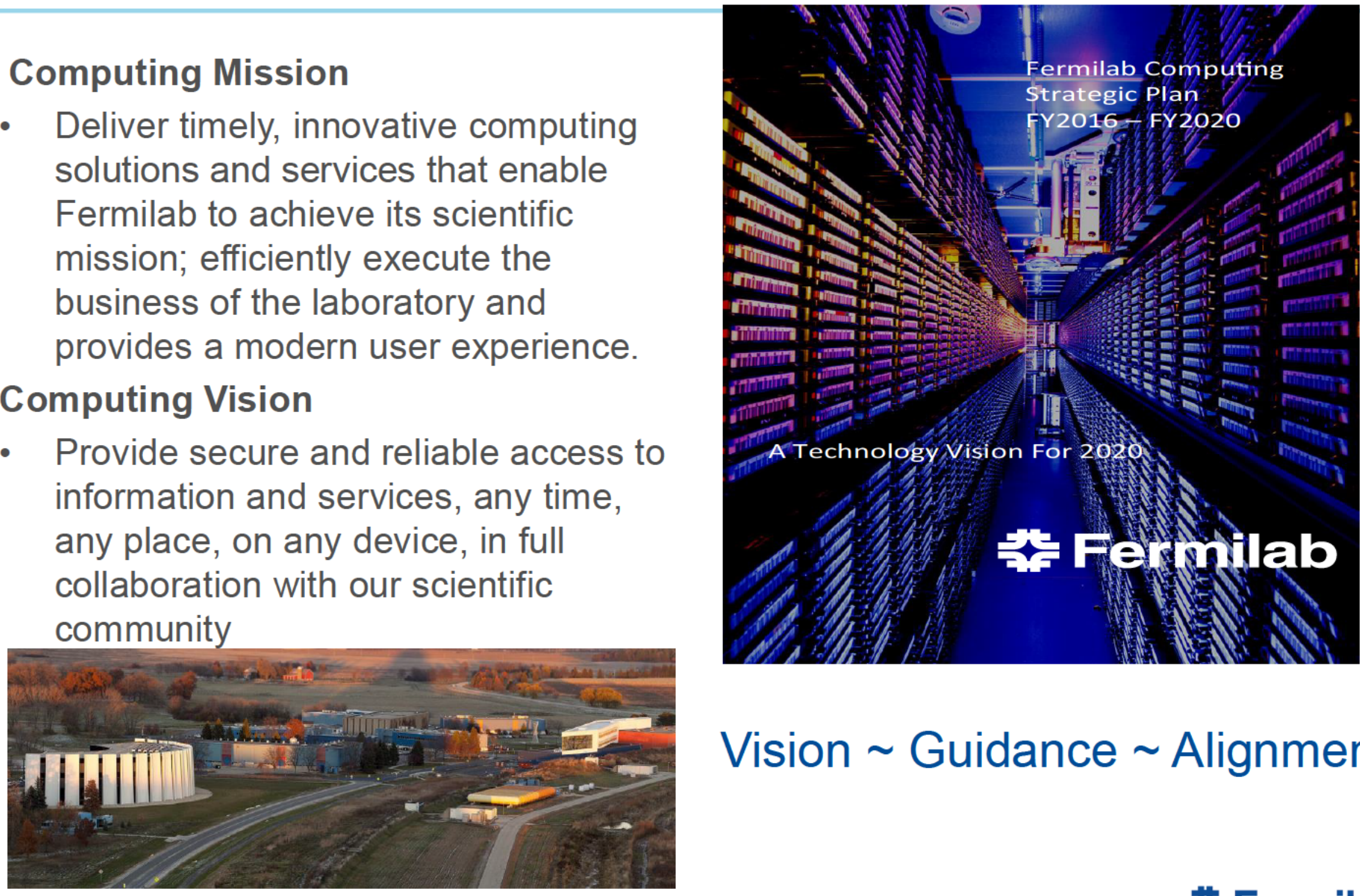

Vision Guidance Alignment 


\section{Financial Management - Service Costing - Maturity model}

\section{Understand the value of computing services}

\section{Enable value capture and creation}

\section{Ensure enhanced decision making}

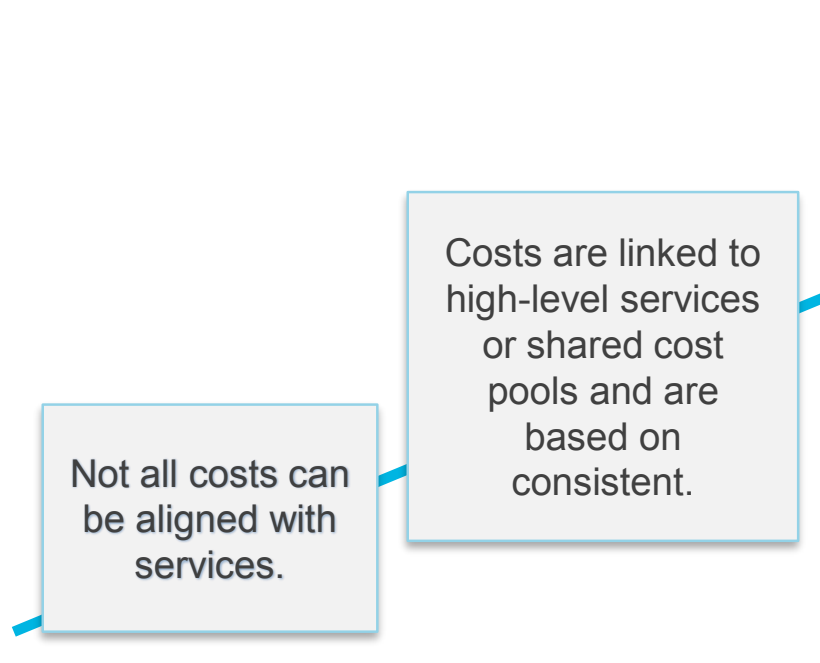

Service Areas overall are

subdivided by

customer,

documenting

utilization in some

form as a basis for allocations.
All Internal and pooled costs are distributed and amortized to just the right services and accuracy is improved.
Costs are portrayed in total for Service Offerings, and unit prices or rates are extracted from the same data. detailed Service

Offerings and specific customerdriven purchase decisions-for the purpose of service improvement and portfolio

management.
Where we are today

\begin{tabular}{|c|c|l|l|l|l|}
\hline \multicolumn{1}{|c|}{$\mathbf{0}$} & \multicolumn{1}{|c|}{ I } & \multicolumn{1}{c|}{ II } & III & IV & V \\
\hline $\begin{array}{l}\text { Traditional } \\
\text { Budgeting }\end{array}$ & Transparency & $\begin{array}{l}\text { Fair } \\
\text { allocations }\end{array}$ & $\begin{array}{l}\text { Demand } \\
\text { management }\end{array}$ & Accuracy & Rates \\
\hline
\end{tabular}




\section{Customer Alignment}

Business Relationship Management identifies the needs of customers and ensures that appropriate services are developed to meet those needs.

Demand Management seeks to understand, anticipate and influence customer demand for services.

Portfolio Management ensures that service providers have the right mix of services to meet required business outcomes at an appropriate level of investment.

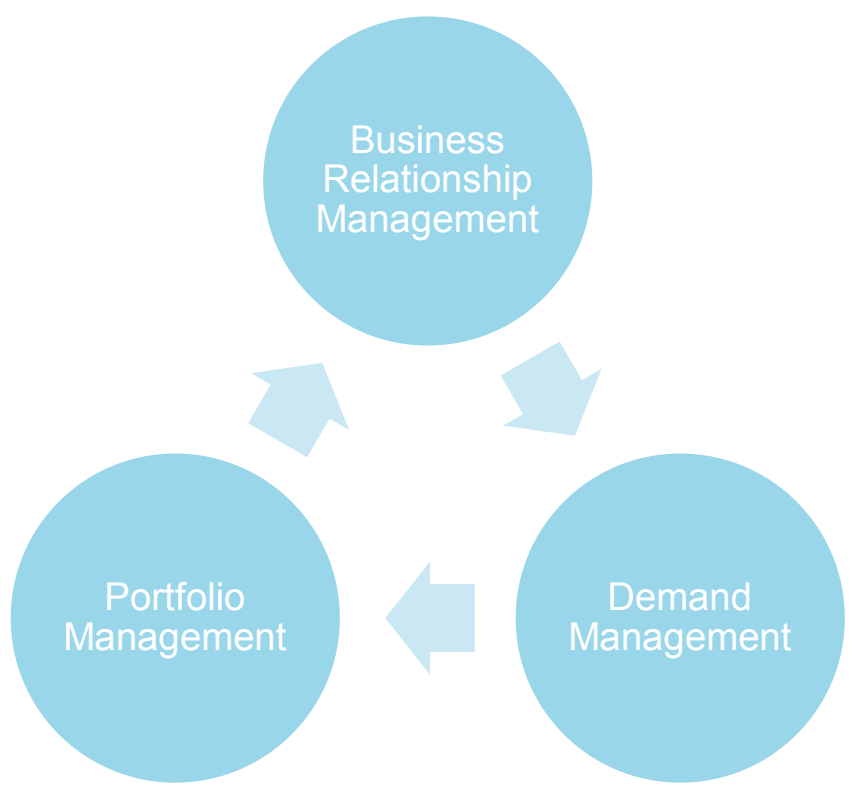




\section{Business Relationship Management}

\section{Active and effective liaisons are key to success}

- Business liaisons have IT management experience as well as business area knowledge and expertise

- Scientific liaisons are scientists that reside in Computing and are embedded within experiments and projects

Advise and assist customers through day-to-day interactions with Computing

- Advocate for divisions, experiments, and/or projects

- Communicate about existing, new and changed services and programs

- Pay attention to ensure issues are addressed in a timely manner
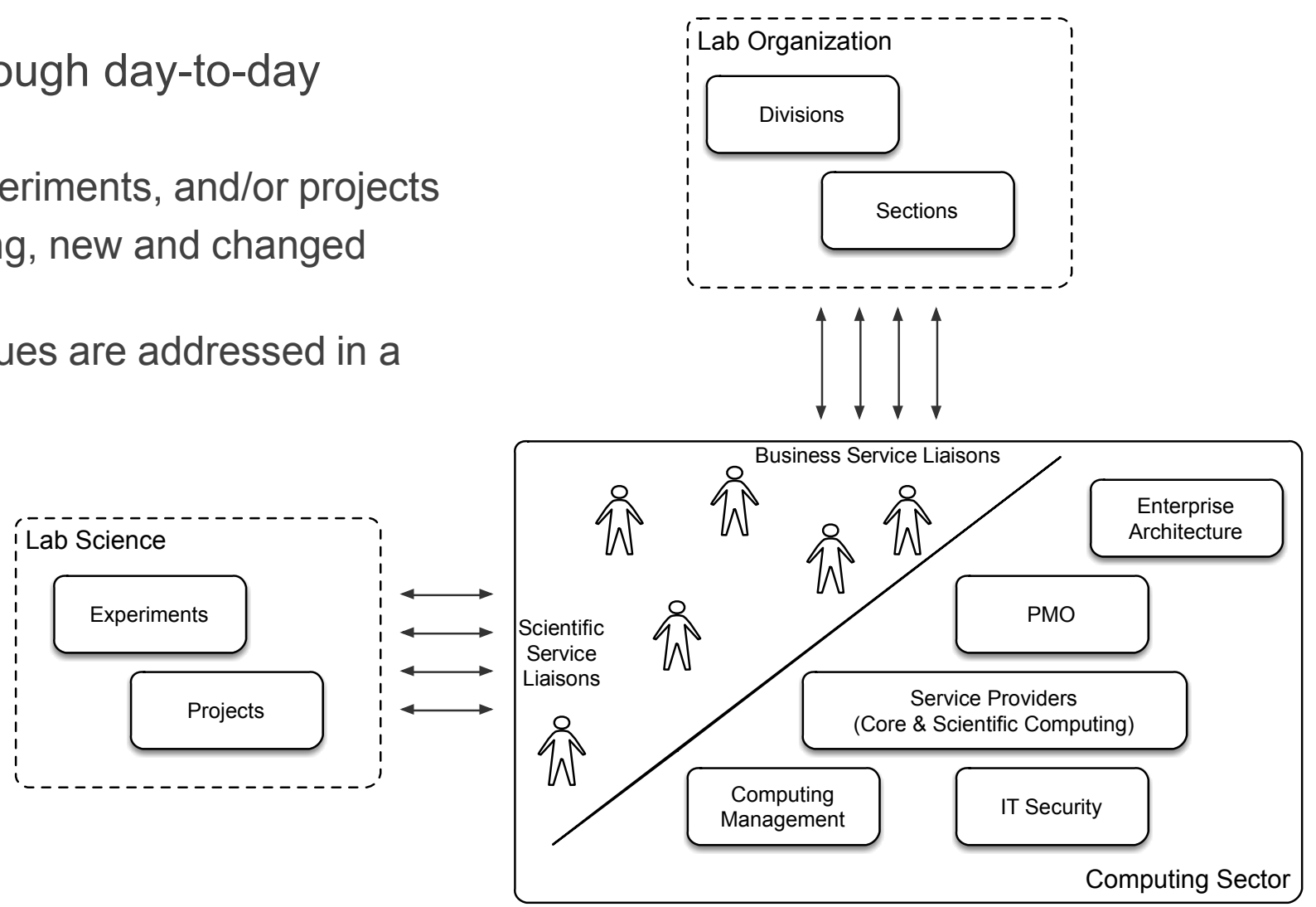


\section{Demand and Portfolio Management}

Implementing Demand Management

- Processes and tools to capture, evaluate and prioritize all demands or requests

- Business Relationship/Portfolio Manager

- Provide the primary and strategic engagement with customers

- Identify, categorize and shape (i.e., "flesh out") all demand

- Route demand requests to the right portfolio or IT fulfillment team

Revitalized Portfolio Management

- Expanded definition of "portfolio" to include projects, releases and operations

- Expanding scope of IT Executive Council to be directly accountable for portfolio decisions (rather than simply consulted)

- Expanding monetary scope of Information Systems portfolio

- Integrated Portfolio Management review and approval processes with Enterprise Architecture and Information Security 


\section{Pulling it All Together - Funnel and Pipe Model}

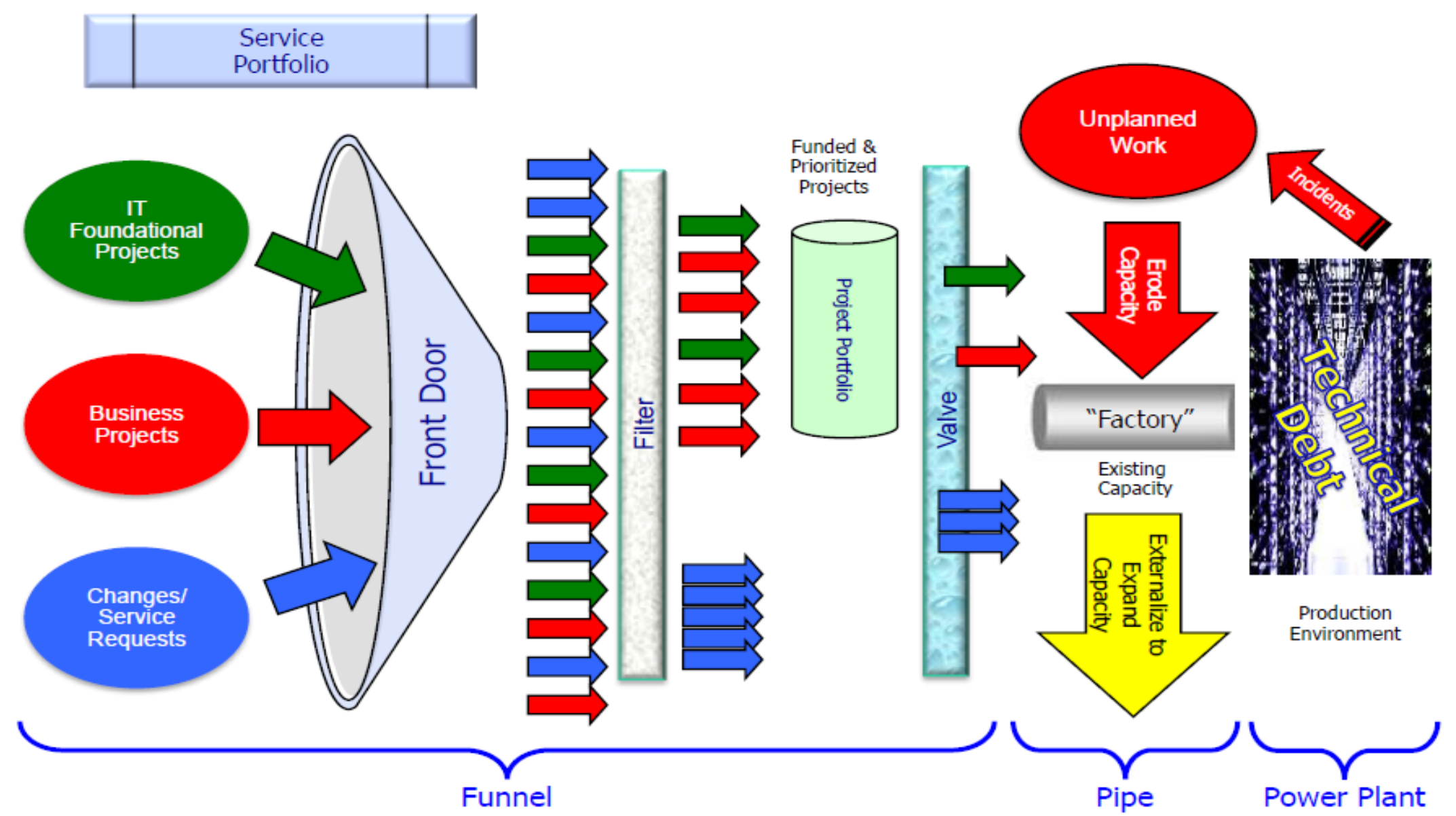

This has been a very effective tool in communicating how this will work

Figure 4

Figure 4. excerpt from MANAGING \& ORGANIZING THE ITSM OPERATING MODEL "Funnel Through The Pipe Into The Power Plant" by Jack Probst, Principal Consultant, Pink Elephant 


\section{Finance Roadmap FY18-CY23}

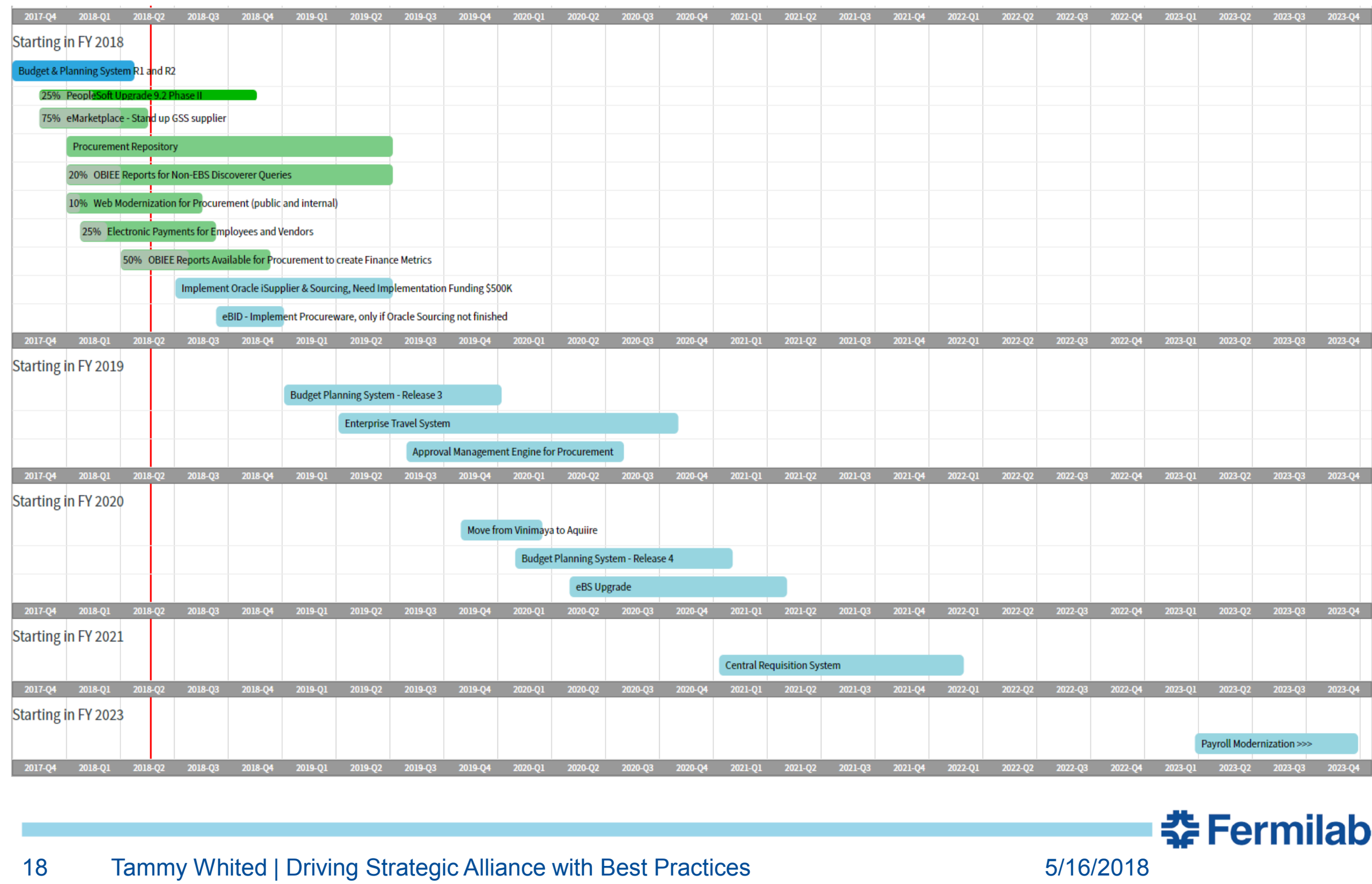




\section{Organization Change Management}

- Formalized for projects in 2015

- Consistent communication is key to any change

- Moving from resistance to acceptance is more than communication

- Important to get involvement from key stakeholders

- Projects require the following:

- Communication plan

- Identify key stakeholders/change agents

- Project talking points

- Customer talking points

- If needed, project website for communicating specifics, posters and other campaigns to get ready for the upcoming change(s) 


\section{Service Design}

- Created a culture focused on Services

- Service 'Blueprint'

- Improved quality and consistency of service

- Leverage existing people, process, technology, procedures

- Easier implementation of new or changed services

- Improved service alignment with business

- Include business functional requirements in the design

- Improved IT governance more effective Service Management and IT processes.

- Process are adaptable. As you design a service, there is likely something we can carry forward and continually make improvements.

- We use service areas to group related services and offerings, from the provider perspective. This lets us consolidate metrics and KPIs down to a reasonable number, and to report on related services together.

- Over time, reduced total cost of ownership 


\section{CIO Story - The Value of IT}

- $\quad$ IT focus is on strategic partnerships, executing and delivering results.

- Better planning and classification of work has increased our ability to execute large projects from $5 \%$ to $30 \%$ of our budget

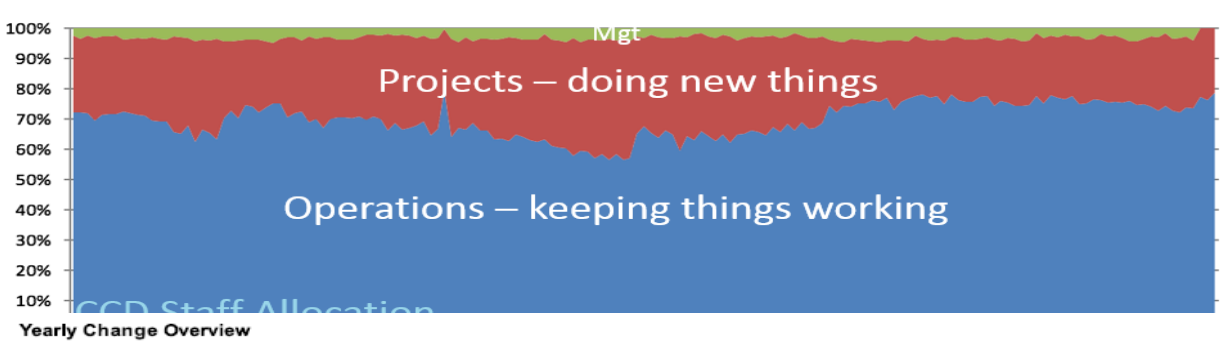

- Standard processes make it easy for people to manage their services.

- Improved quality of services and less downtime due to changes.

- We have 49 Service Areas, 272 offerings; 117 of these are ISO certified.

- We are doing more with less. Supplier management has helped us to absorb the financial shortfalls of reduced and flat/flat budgets.
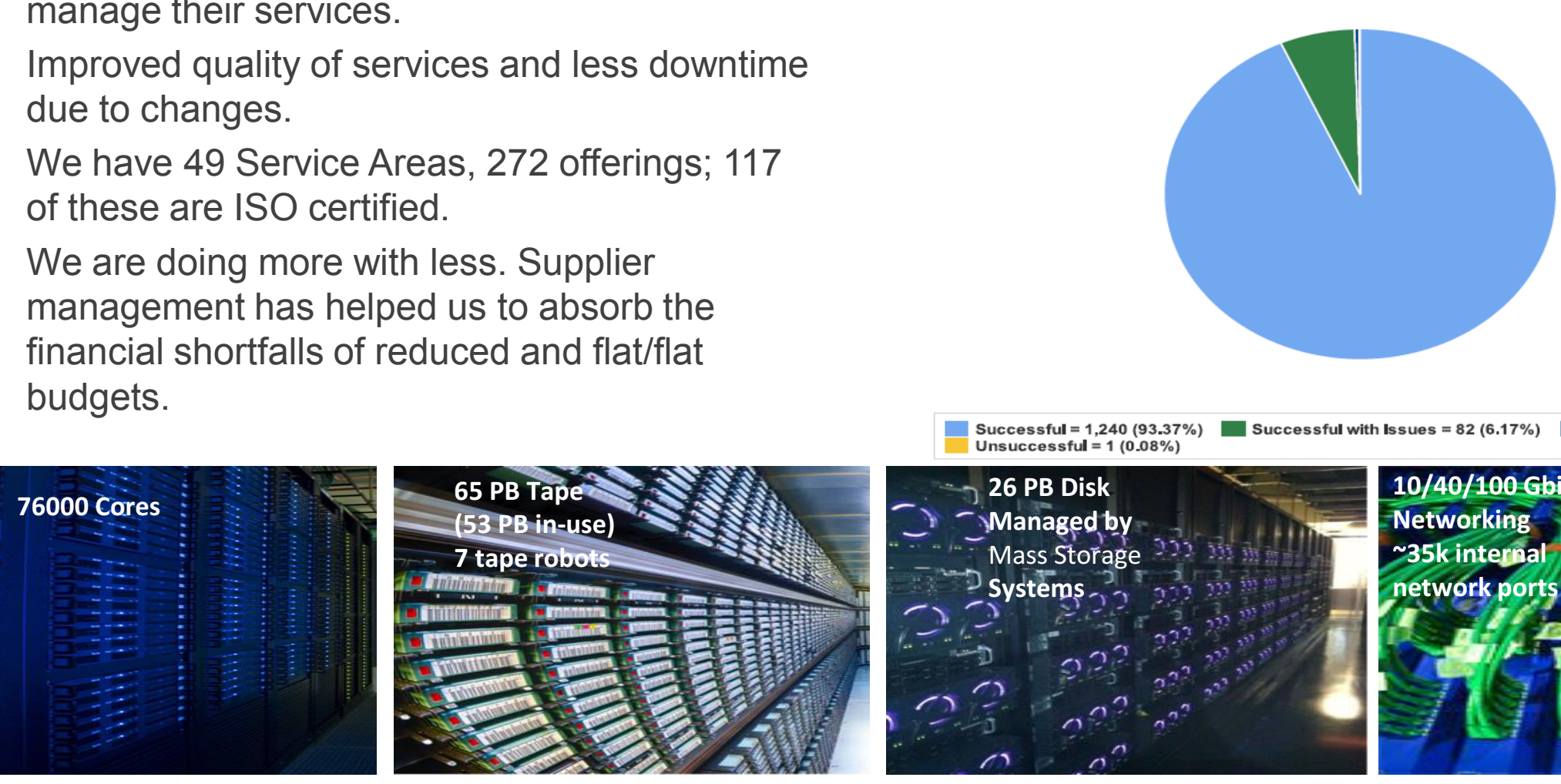
Successful = 1,240 $(93.37 \%)$
Unsuccessful = $1(0.08 \%)$
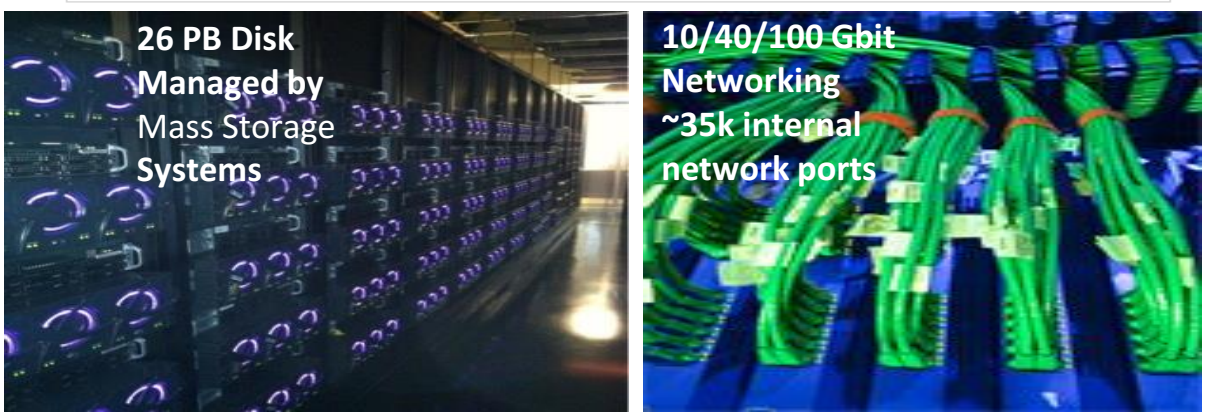


\section{Computing Operating Model}
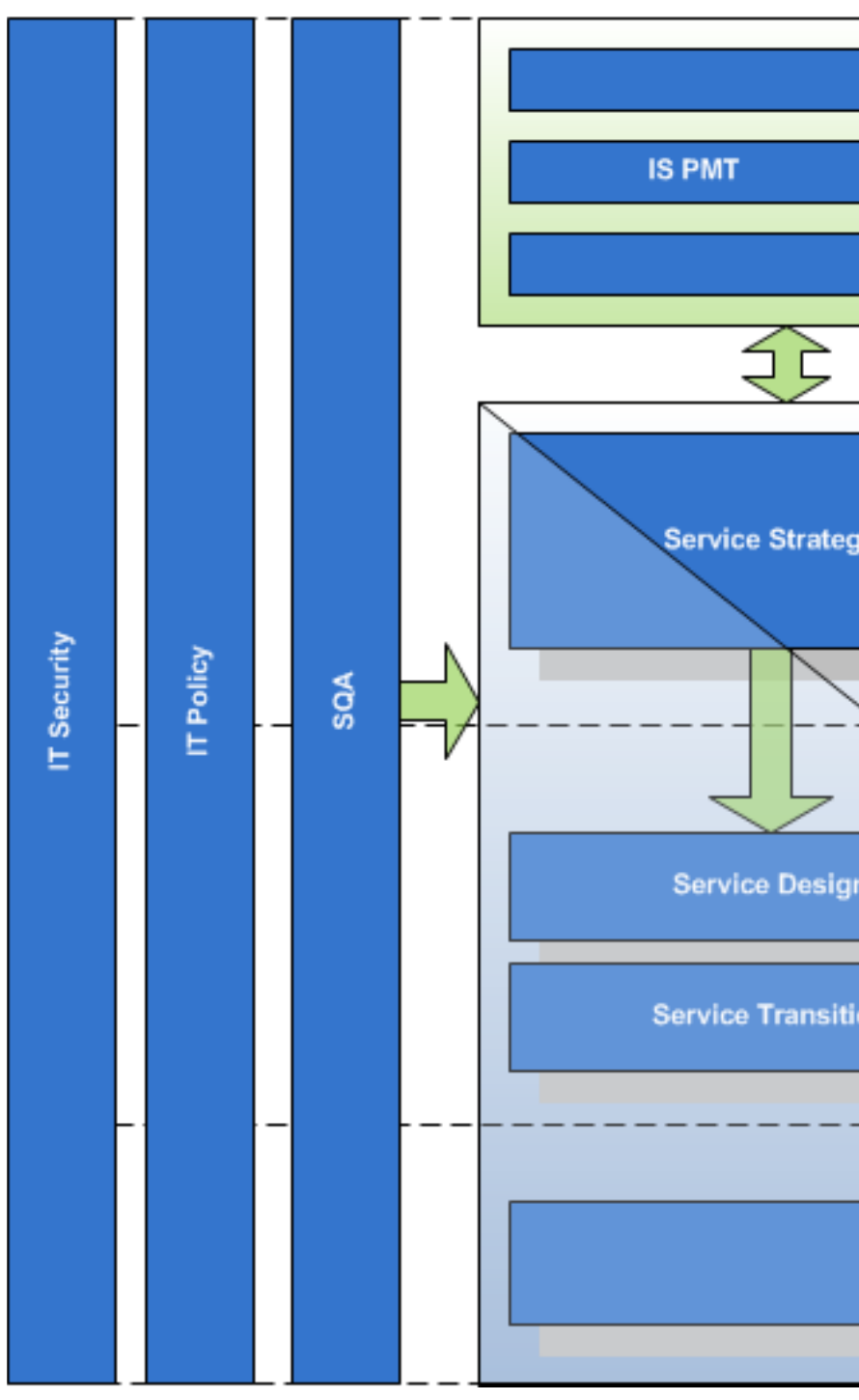

IT Executive Council

IT PMT

Sci PMT
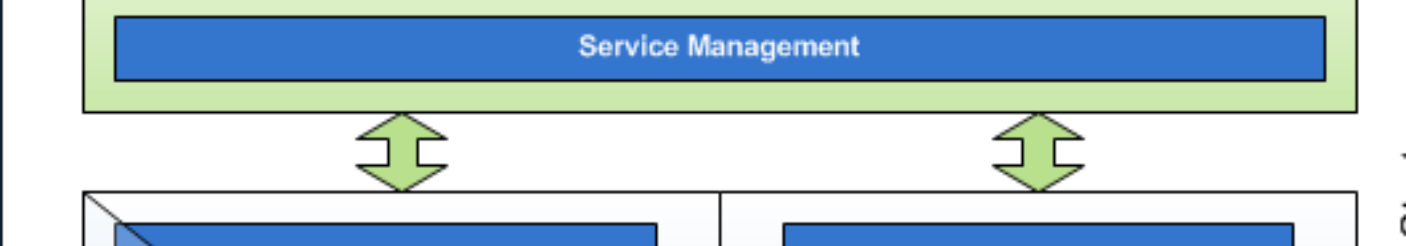

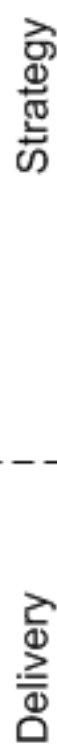

Service Transition

Solution Delivery

Enterprise Architecture

\section{Service Design}
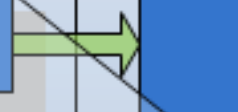

\section{(}

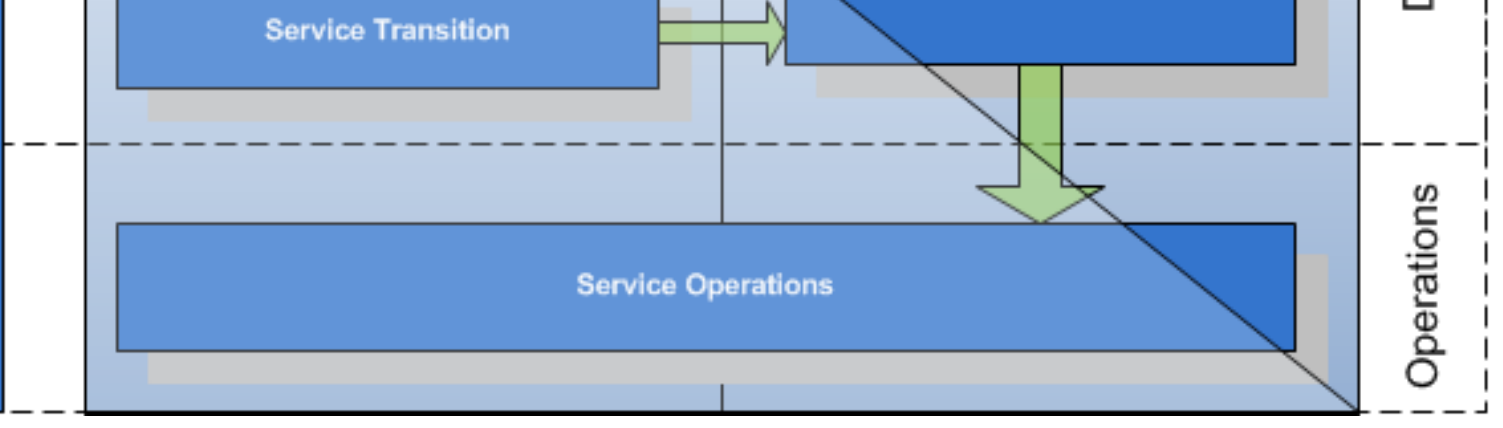




\section{Next on Fermilab Journey}

- Deliver agreed projects from the roadmaps

- Continue building Organization Change Management

- Fully implement Demand Management for all business areas and service teams

- Service Costing to the next maturity step

- Full ISO20K recertification is "No Op"- where we don't do anything but our normal work to prepare for the auditors.

- Improved training and tools for service providers 


\section{Results}

- Agility to respond to the changing needs of the experiments and projects

- Continue to provide the premier computing centers and tools for experiments (CMS, DUNE, NOvA, etc.)

- Transform the enterprise to make information more accessible

- Broader benefits

- High Energy Physics community with HEP Cloud

- Machine Learning

- Quantum Computing

- Lower stress level - staff knows what is expected of them and when and how to navigate the landscape

- Strategic Partnerships with the business and science 


\section{Key Takeaway}

- Fundamentals allow Strategy to lead

- Organization Change Management is here to stay

- Strategic Alignment takes commitment

- The North Star - Strategic Partnerships

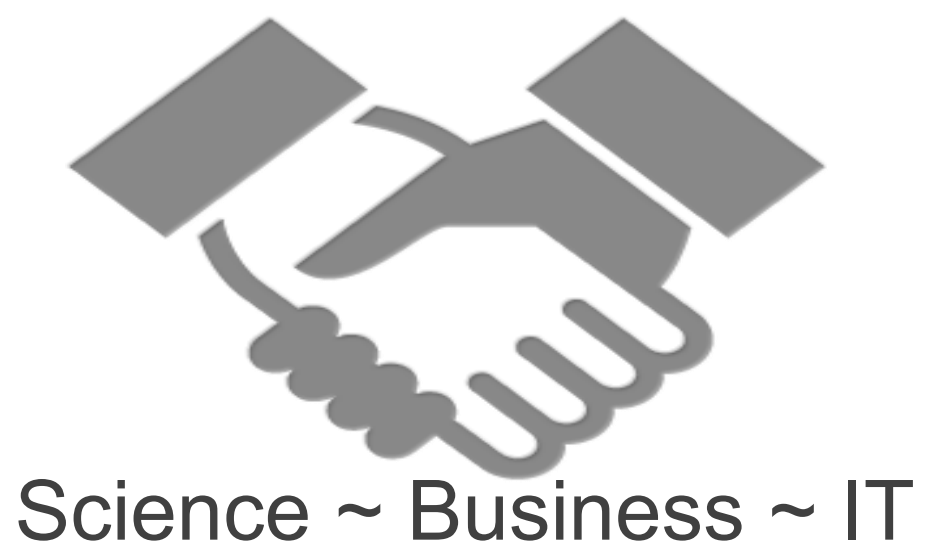




\section{Always leave with the Bison}

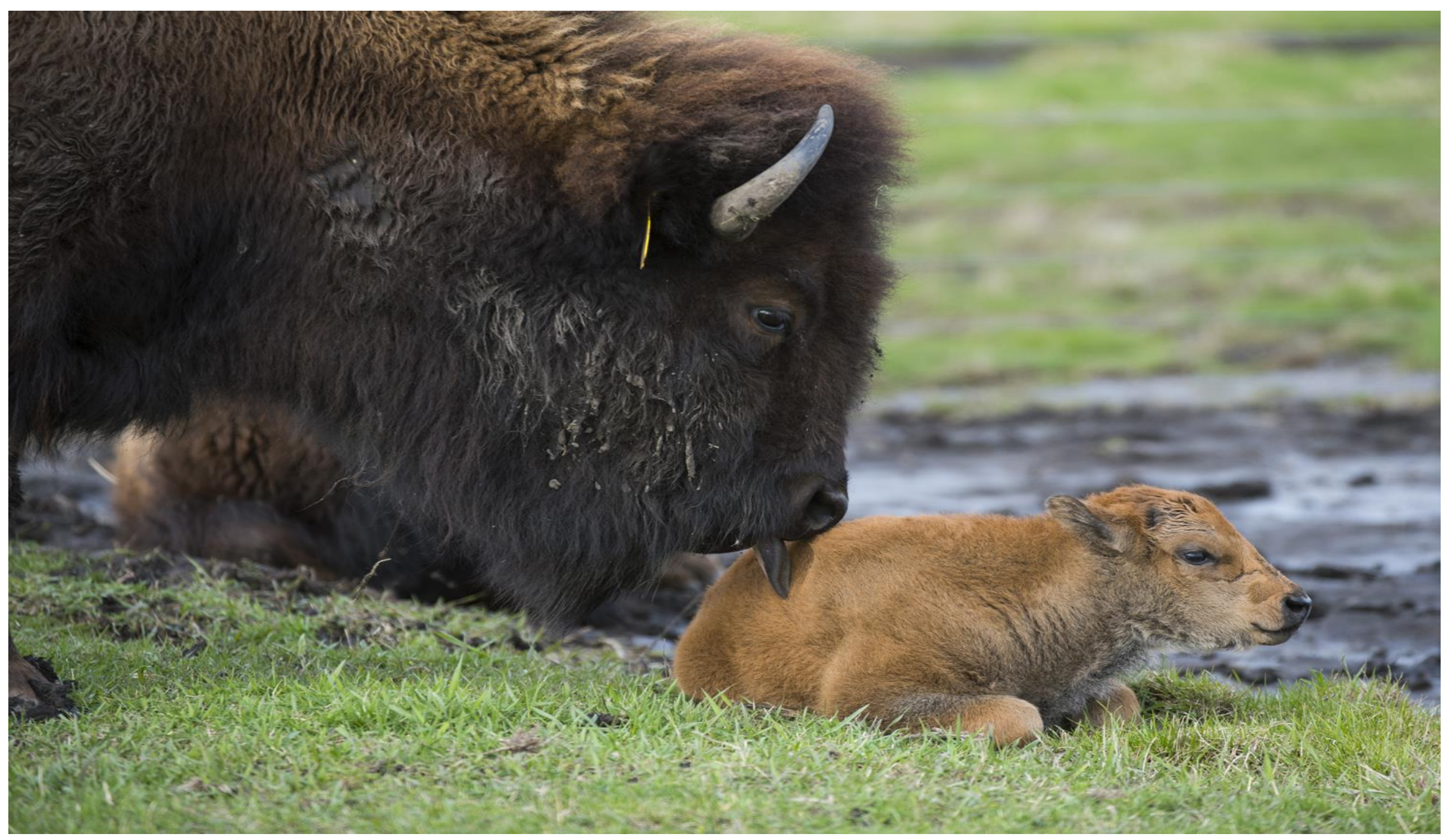

\section{葉Fermilab}




\section{Questions?}

\section{Presented by:}

Tammy Whited

Fermilab

twhited@fnal.gov

630-840-8613

Thanks to my Service Management team and Computing management for the support we have for the program. 